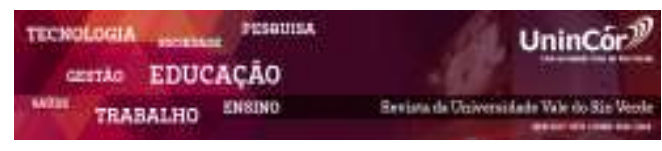

Revista da Universidade Vale do Rio Verde ISSN: 1517-0276 / EISSN: 2236-5362 v. 16 | n. 2 | Ano 2018

Sérgio LuísAllebrandt UNIJUI allebr@unijui.edu.br

Nedisson Luís Gessi FEMA

nedisson@fema.com.br

Nelson José Thesing

UNIJUI

nelson.thesing@unijui.edu.br

Mauro Alberto Nuske

SETREM

mauronuske@gmail.com

Airton Adelar Mueller

UNIJUI

airton.mueller@unijui.edu.br

Patrícia Rodrigues da Silva SETREM

silva.pati_22@hotmail.com

\section{ADMINISTRAÇÃO PÚBLICA E POLÍTICAS PÚBLICAS: O PROGRAMA PRIMEIRA INFÂNCIA MELHOR UMA INOVAÇÃO EM POLÍTICA PÚBLICA}

\section{RESUMO}

O estudo verifica a administração pública em três níveis organizacionais: o patrimonialista, burocrático e o gerencial. Contempla as tendências de um novo modelo conhecido como societal, de participação da sociedade civil no processo da gestão governamental. Ainda, verifica os principais conceitos e elementos constitutivos das políticas públicas. Para responder aos desafios propostos, o caminho metodológico contempla a pesquisa qualitativa, as fundamentações teóricas, documentais, ao investigar as administrações públicas e seus modelos básicos, bem como, a compreensão dos conceitos e elementos constitutivos das políticas públicas. Buscou-se evidenciar o Programa Primeira Infância Melhor (PIM) como uma inovação em política pública. Por fim, a contribuição desse estudo permite reforçar a importância do ciclo da política pública como principal esquema heurístico utilizado para analisar políticas públicas, e o PIM como um modelo a ser seguido como referência para a criação do recente Marco Legal da Primeira Infância, para fortalecer as ações voltadas ao infante de zero a seis anos de idade, o fortalecimento do vínculo e convivência familiar.

Palavras-Chave: Administração Pública. Políticas Públicas. Primeira Infância Melhor. Inovação. Saúde.

\section{PUBLIC ADMINISTRATION AND PUBLIC POLICIES: THE FIRST CHILDHOOD PROGRAM BEST INNOVATION IN PUBLIC POLICY}

\begin{abstract}
The study verifies the public administration in three organizational levels: the patrimonialist, bureaucratic and the managerial.It contemplates the tendencies of a new model known as societal of civil society participation in the process of governmental management.Also it verifies the main concepts and constitutive elements of public policies.In order to respond to the proposed challenges, the methodological path includes qualitative research, theoretical and documentary foundations, investigating public administrations and their basic models, as well as understanding the concepts and constitutive elements of public policies.It seeks to evidencethe Early Childhood Program (PIM) as an innovation in public policy.Finally, the contribution of this study reinforces the importance of the public policy cycle as the main heuristic scheme used to analyze public policies, and the PIM as a model to be followed as a reference for the creation of the recent Legal Framework for Early Childhood to strengthen the actions aimed at the infant from zero to six years of age, the strengthening of bond and family coexistence.
\end{abstract}


Keywords: Public Administration. Public Policies. Best Early Childhood. Innovation. Health.

Recebido em: 09/08/2018 - Aprovado em: 09/12/2018 - Disponibilizado em: 15/12/2018

\section{INTRODUÇÃO}

A partir de uma perspectiva histórica, a administração pública como ciência administrativa teve os Estados Unidos como um ambiente inicial para desenvolver as teorias organizacionais, que se consolidaram como uma disciplina. Significa que a administração pública, por um longo período era vista, apenas, como formadora de servidores públicos para execução de atividades fins, onde inicialmente o administrador era tido como executor de políticas que mais tarde passou a assumir o papel de formulador de políticas públicas.

Nesse contexto destacam-se algumas transformações na administração pública brasileira, com a criação do Departamento Administrativo do Serviço (DASP), órgão público do governo federal, criado pelo decretolei $\mathrm{n}^{\mathrm{o}} 579$, de 30 de julho de 1938, durante o governo de Getúlio Vargas (período do Estado Novo). O esforço da reforma já estava previsto na constituição de 1937. Além de fornecer elementos para melhoria da máquina pública, para fornecer assessoria técnica ao presidente da república e elaborar a proposta orçamentária.

Outra importante mudança foi à fiscalização do orçamento a partir de 1945. Após a queda de Getúlio Vargas (1946), houve a realização de concursos para o funcionalismo federal.

Com o governo militar foi alterado o Departamento Administrativo do Pessoal Civil, por força do decreto-lei $\mathrm{n}^{\mathrm{o}} 200$, de 25 de fevereiro de 1967, definindo a sua incompetência para as questões do serviço público na esfera das Forças Armadas. Significa o retorno à antiga denominação por lei $n^{\circ} 6.228$, de 15 de julho de 1975. Ainda, através do decreto no 91.147 , de 15 de março de 1985, passou a se vincular ao Ministro de Estado Extraordinário para Assuntos de Administração, deixando de ser o órgão de assessoramento imediato do Presidente da República. Com o decreto no 93.211, de 03 de setembro de 1986, o órgão é extinto e substituído pela Secretaria da Administração Pública da Presidência da República (SEDAP).

Com a promulgação da constituição de 1988 ocorreram mudanças tanto na estrutura administrativa quanto na dimensão política, buscando a inserção da sociedade na formulação de políticas públicas e na gestão governamental. E por fim, nos anos 90 as grandes transformações sociais, políticas econômicas e principalmente tecnológicas impulsionaram a adoção de um modelo que atendesse essas transformações, optou-se então pelo modelo gerencial que tem como principal fundamento a busca da eficiência.

A partir do modelo gerencial a administração pública busca constantemente propor novas soluções para novos tempos. Surgem então novas possiblidades no contexto da administração pública que visam reduzir a ênfase na tecnicidade nos processos de decisão e 
ampliam os mecanismos de participação popular, fazendo com que a sociedade civil passe a ocupar uma posição de destaque que segundo Allebrandt (2002), o cidadão é parte integrante do processo de construção e formulação de políticas públicas.

As transformações ocorridas na administração pública têm implicações diretas nas políticas públicas, uma vez que o governo se estrutura e se organiza para cumprir com seu papel central, que é, de buscar soluções que atendam as demandas da sociedade, uma vez que as políticas públicas envolvem a escolha, por parte do governo, de fazer algo ou não fazer, dessa forma, as políticas públicas sempre serão um desafio para o poder público.

Nessa perspectiva, o estudo verifica os vários processos da administração pública, ao evidenciar os três modelos básicos de administração: o patrimonialista, o burocrático, e o gerencial. Ainda, a administração pública e a importância do Estado, para compreender as questões referentes às políticas públicas $\mathrm{e}$ posteriormente contemplar o programa PIM que é uma inovação no Brasil, sancionada pela lei 13.257/2016 que prevê na "primeira infância", o dever legal do poder público, em formular e executar essas políticas que atendam de forma integral a garantia da qualidade de vida digna na primeira infância.

\section{ADMINISTRAÇÃO PÚBLICA}

Tendo como ponto de partida a Segunda Guerra Mundial, momento histórico em que se ampliam as visões das ciências administrativas ou organizacionais, especialmente nos Estados
Unidos, com o surgimento das teorias organizacionais conhecidas como as teorias clássicas ou tradicionais. Assim, a administração pública teve uma trajetória que ao longo do tempo passou a se consolidar como disciplina.

Para Saravia eszl Ferrarezi (2006) os estudos pioneiros de administração pública foram os de Woodrow Wilson, professor de Ciências Políticas da universidade de Priceton. Os estudos tinham como objetivo a criação de uma classe administrativa apartidária, focada no mérito, para, assim, neutralizar o nepotismo e favoritismo que pairavam sobre a administração pública. Nessa época o administrador público era tido como um mero executor de políticas, posto que, com o crescimento do aparato estatal houve uma mudança do conceito de administrador, já entendido como formulador de Políticas Públicas.

A base de formação da disciplina de administração pública foi à administração científica, um modelo de administração criado pelo americano Frederick Winslow Taylor no fim do século XIX e início do século XX e que se baseia em melhor custo/benefício aos sistemas produtivos.

Para Farah (2011) a Administração Pública, como área de formação e campo de estudos teve como foco a preparação de servidores públicos, para execução de atividades fins, e a implementação de políticas públicas: orçamento, gestão de pessoal e organização para a administração pública moderna. Assim a administração pública era tida como governamental, com a função de formar quadros de servidores para o Estado. 
Com as crescentes transformações sociais, políticas e econômicas, a administração pública teve uma nova definição, ou seja, ampliou suas fronteiras para além do Estado, inclusive passou a incluir organizações não governamentais, privadas, orientadas para prestação de serviço público, entidades do setor privado e da comunidade, instituições de cunho inclusivo e participação do cidadão no processo de formulação, implementação e controle de políticas públicas, o que impulsionou os estudos acerca da disciplina de políticas públicas.

No entender de Rabell (2000), o deslocamento do público para além do Estado e a dissolução da fronteira entre o público e o privado contribuiu para aumentar a complexidade das políticas públicas de tal forma, que a administração pública precisou se reposicionar nesse contexto para dar conta de tal complexidade imposta por mudanças paradigmáticas.

Para Farah (2011) a incorporação das políticas públicas como objeto de análise pela administração pública, aproxima a administração dos estudos nas ciências políticas. Significa, verificar as novas dinâmicas das atividades estatais, repensar seu papel, olhar para as políticas sociais e econômicas em um mundo globalizado, onde as empresas precisavam desenvolver novas estratégias para continuarem competitivas, em um mundo cada vez mais tecnológico e inteligente, graças aos avanços das tecnologias de comunicação e informação. Para Grau (2004) abre possibilidades para uma maior participação da cidadania na vigilância das organizações estatais. Os avanços facilitaram a participação democrática nas decisões estatais, na sua implementação, no seu controle e nos seus benefícios, de modo a fortalecer a transparência e o consequente controle social das ações do Estado (SARAVIA; FERRAREZI, 2006).

\subsection{A Administração Pública no Brasil}

No Brasil, a exemplo do que ocorreu nos Estados Unidos a administração pública teve seu início atrelado ao objetivo de treinar servidores para a administração pública moderna. Segundo Farah (2011), até meados de 1930 a administração pública no país ainda estava vinculada a tradição da legislação romana que foi introduzida pela colonização portuguesa, ou seja, até a década de 1930, na Administração Colonial, no Império Brasileiro e na $1^{\text {a }}$ República, em 15 de novembro de 1889, onde o patrimonialismo foi a tônica do fazer público. A administração foi marcada pela troca de favores, mistura do público e do privado e pela baixa capacidade de ação local, pois a administração local ficava subordinada à metrópole.

No entender De Paula (2005a) no Brasil, devido à tradição patrimonialista, os empregos e benefícios que se auferem do Estado costumam estar ligados aos interesses pessoais e não aos interesses públicos. Esse personalismo do serviço público brasileiro relaciona-se com a ética de fundo emotivo que permeia a nossa cultura: o "homem cordial" é avesso à impessoalidade e ao formalismo e, consequentemente, à burocracia.

Assim, percebe-se que a tradição formal, na época, era de ordem jurídica, fortemente articulada pelo patrimonialismo e pelo clientelismo. Para responder a esse desafio, na 
década de 1930, teve início à busca da consolidação de uma administração Pública moderna, com o propósito de instaurar os serviços públicos a luz dos moldes da burocracia Weberiana, segundo Farah (2011).

Na ditadura Vargas, entre 1930 e 1945, quando governou o Brasil por 15 anos e de forma contínua, o Estado assumiu a liderança do processo de modernização econômica e social do país, intervindo na produção e criando um modelo desenvolvimentista que levou a uma ruptura do tradicional sistema patrimonialista e abriu espaço para o desenvolvimento de uma administração pública baseada na burocracia, conceito sugerido por Max Weber que pode ser explicado, conforme Oliveira (1970, apud BIEGER et al.,2017):

O conceito weberiano de burocracia é resultante da concepção weberiana de autoridade legal. Suas raízes emergem da problemática do poder, sua origem e legitimidade, sua estrutura organizacional e funcionamento, sua eficácia e destinação e, por fim, suas consequências. Burocracia designa, em Weber, um quadro de funcionários que, organizados dentro de uma forma específica e submetidos a normas de conduta também específicas e determinadas, exercem autoridade legal (p. 47).

As reformas administrativas de 1937 tiveram como marco inicial da administração pública, a criação da Revista do Serviço Público e a fundação do Departamento de Administração do Setor Público (DASP), para modernizar a gestão. De acordo com Bieger et al., (2017), essa nova realidade fez com que a administração se profissionalizasse, no entanto, os procedimentos administrativos baseados na burocracia não conseguiram se adaptar muito bem a uma sociedade até então acostumada com favores e troca de influências. Porém, em meados de 1940, as investigações na administração pública, conquistam seu espaço ao instalar no Rio de Janeiro a Fundação Getúlio Vargas (FGV).

O período compreendido entre 1967 até o final de 1970 ainda era fortemente influenciado pelo paradigma da administração pública como ciência administrativa, marcado pela separação entre administração e política, que segundo Farah (2011) tinha como característica predominantemente a valorização de técnicas administrativas como instrumentos de mudanças importantes para o desenvolvimento.

Ainda que, inicialmente, eficaz e com excelentes níveis de desenvolvimento por muitos anos, o modelo burocrático começou a se tornar obsoleto devido a influência de fatores externos e internos, a partir da crise do petróleo na década de 1970, quando os governos perceberam que era necessário repensar o modelo burocrático, uma vez que, o mesmo era rígido e intervencionista.

No início dos anos 1980, no cenário nacional, se afirmar a participação popular no processo decisório, especialmente nas políticas públicas. Esse movimento consolida a participação, tanto nas práticas sociais, como nas produções acadêmicas, superando em boa parte, a concepção de um Estado Mínimo, que indicava a presença do estado tão somente na educação, na saúde e na segurança, no entender de Gomes e Oliveira (2010).

A partir de 1990, o Estado Brasileiro se atenta para a realidade da competição global. Caracterizada pela abertura dos capitais e comércio internacional, associada a privatização 
das empresas estatais e a redução da ação do Estado sobre a economia. Segundo Gomes e Oliveira (2010), nesse momento ocorre uma redefinição do papel do Estado, de um modelo paternalista, empresarial e burocrático para um papel de gestor. Momento propício para Administração Pública gerencial, também conhecida como Nova Administração Pública, emergir como modelo ideal para o gerenciamento do Estado brasileiro.

As reformas dos anos de 1990 fomentaram duas vertentes da Administração Pública: uma gerencial alinhada ao movimento internacional impulsionado pelo Reino Unido e pelos Estados Unidos, e uma societal que herdou as propostas do movimento pela redemocratização no Brasil (DE PAULA, 2005a). A administração societal se baseia em experiências alternativas de gestão pública por meio dos conselhos gestores e orçamentos participativos, buscando uma gestão pública social.

Com a elaboração da constituição de 1988, no embate de diferentes forças políticas que apresentaram propostas para elaboração de um novo referencial de Estado e sociedade, na intenção da construção de uma sólida democracia no Brasil. Segundo De Paula (2005a) os movimentos da época envolviam sindicatos, movimentos populares, ONGs e entidades profissionais todos focados na busca da cidadania e do fortalecimento do papel da sociedade civil na vida política do país.

A última grande reforma administrativa ocorreu em 1995, no governo Fernando Henrique Cardoso, levada a cabo pelo ministro Luís Carlos Bresser-Pereira, pesquisador reconhecido no setor público e teve como principal fator a adoção do Gerencialismo na administração pública brasileira.

Secchi (2009) e De Paula (2005a), afirmam que uma Administração Pública mais assertiva é aquela que atenda o real interesse do cidadão e que tenha a participação social. Mesmo os últimos governos têm mantido algumas dessas medidas da última reforma como “a orientação para o cidadão, flexibilização das estruturas e ênfase em desempenho" (COSTIN, 2010, p. 70).

Assim, ao longo dos anos 90 os movimentos que eram predominantemente societal almejavam a implementação de um projeto político que ampliasse a participação dos atores sociais de forma a criar instrumentos para exercer um maior controle social sobre as ações estatais, descentralizando a definição e implementação das ações públicas. "Consolidava-se assim o modelo societal: a reforma do Estado não é somente uma questão administrativa e gerencial, mas sim um projeto político" (PAULA, 2008, p.155 apud GOMES; OLIVEIRA, 2010).

Após um breve entendimento acerca da administração pública é importante que se compreenda também os modelos organizacionais de administração pública no contexto mundial e nacional.

\section{MODELOS ORGANIZACIONAIS DE ADMINISTRAÇÃO PÚBLICA}

$$
\text { Para Amato (1971, p. 15) a }
$$

Administração Pública poderá ser "a fase do governo que consta da cooperação ordenada de pessoas, mediante o planejamento, organização, 
educação e direção de seu comportamento, para a realização dos fins do sistema político".

Já para Silva (2013) a Administração Pública contempla um conjunto de órgãos e de servidores que, mantidos com recursos públicos, são encarregados de decidir e implementar as normas necessárias ao bem-estar social e das ações necessárias à gestão da coisa pública.

Portanto, os modelos organizacionais de administração pública são resultados conquistados por um conjunto de métodos administrativos, que são dinâmicos e tendem a modificar de acordo com as especificidades de cada organização. Assim, a evolução da administração pública pode ser entendida como processo de aperfeiçoamento dos serviços prestados pelo Estado à população, que pode ser representada por três modelos: administração patrimonial, administração burocrática e administração pública gerencial. Nesses modelos, o objetivo é suprir uma deficiência do modelo anterior, introduzindo novos conceitos ou mudando conceitos ineficientes ao aparelhamento do Estado, segundo Silva (2013).

\subsection{Administração Pública Patrimonialista}

A administração pública patrimonialista é típica dos Estados absolutistas do século XVIII, tendo como característica marcante desse modelo à dificuldade do administrador em distinguir o patrimônio público de seus bens privados. De forma que o aparelho estatal era tratado como extensão do poder soberano. $\mathrm{Na}$ visão patrimonialista o fundamento primordial era que a administração pública deveria servir a população, onde os governantes consideraram o
Estado como seu patrimônio, havendo uma total confusão entre o que é público e o que é privado, no entender de Silva (2013).

Como consequência desse pensamento, a corrupção e o nepotismo são facilitadas pelo modelo patrimonial. Para Gomes e Oliveira (2010, p.110) "o fato de o patrimonialismo afetar a finalidade básica do Estado de proteger a coisa pública, pois as atividades públicas deixam de estar empenhadas com a melhor relação custobenefício possível para a sociedade". Com o crescimento do pensamento capitalista a sociedade e o mercado se distinguiram do Estado, e a necessidade de estabelecer uma separação entre o político e o administrador público fez com que o modelo patrimonialista se tornasse ineficiente e inaceitável. É a partir disso, que surge a administração burocrática racional-legal moderna ou modelo burocrático.

\subsection{Administração Pública Burocrática}

A administração pública burocrática foi adotada para suprir a administração patrimonialista, no entender de Silva (2013), surgiu basicamente com o advento do Estado Liberal, que busca romper com o modelo anterior, patrimonialista, pois separa os interesses pessoais do detentor do poder e os instrumentos colocados à disposição do Poder Público para garantir a satisfação do interesse público.

Para Weber (2009) a burocracia é um tipo de poder, é um sistema racional, implementa o formalismo, a existência de normas escritas, a estrutura hierárquica, a divisão horizontal e vertical de trabalho. Assim, têm-se três 
características básicas desse modelo: a formalidade, a impessoalidade e o profissionalismo que para Weber (2009), tais características tornam a burocracia capaz de alto grau de eficiência. No entanto, esse modelo recebeu críticas como a de que, o pressuposto da impessoalidade na verdade dissimula as reais motivações dos burocratas, modelo baseado no formalismo e na presença de normas e rigidez de procedimentos limitando a eficiência, os direitos civis e sociais continuaram sem proteção para Gomes e Oliveira (2010).

Em síntese a administração burocrática era cara, lenta, pouco ou nada orientada para o atendimento das demandas do cidadão, ou seja, esse modelo não mais atendia as necessidades da administração pública em uma sociedade que estava em plena era das inovações tecnológicas e da globalização. Surge então, o modelo gerencial como forma de atingir a excelência administrativa com foco no cidadão.

\subsection{Administração Pública Gerencial}

Para Silva (2013) a necessidade de uma administração pública gerencial se apresentava como uma alternativa de correção para alguns problemas do modelo burocrático e que pudesse atender as novas necessidades dos cidadãos em um mundo cada vez mais globalizado, com o abandono dos sistemas baseados na rígida hierarquia burocrática. $\mathrm{O}$ foco da administração gerencial era o aumento da qualidade dos serviços e a redução de custos. Na administração gerencial o comprometimento com o resultado torna-se um instrumento que promove mecanismos de responsabilidade. Conforme Gomes e Oliveira (2010):

A administração gerencial pode ser
considerada um sistema baseado na
racionalidade instrumental aplicada
à gestão pública, tendo como
preceitos organizacionais: a
desagregação do serviço público em
unidades especializadas e centros de
custos; competição entre
organizações, tanto públicas quanto
privadas; o uso de práticas de gestão
advindas da administração privada;
atenção à disciplina e economia e
administradores empreendedores
(p.115).

Corrobora Silva (2013), ao apontar o modelo gerencial para incorporar as mudanças ocorridas nas estruturas organizacionais, na redução da máquina estatal, redução de custos, descentralização dos serviços públicos, da criação de agências reguladoras e a busca pela padronização dos processos que visem otimizar tempo e recursos.

Para De Paula (2005b) a administração pública gerencial ou Nova Gestão Pública é um modelo normativo pós-burocrático, baseado nos valores de eficiência, eficácia. A Nova Administração Pública supõe mudanças na perspectiva sobre a maneira de alcançar resultados, visa contribuir de forma significativa para o aumento da igualdade do acesso aos serviços públicos, requer planejamento estratégico das ações a serem desenvolvidas pelo poder público, maior autonomia gerencial, elaboração de indicadores de desempenho. Além disso, a sociedade passa a atuar na busca de recursos públicos, de forma transparente onde os cidadãos participam do debate público, com o objetivo de garantir que os direitos da coletividade se façam valer (SILVA, 2013). 
Já em 2002, Allebrandt apontava que a sociedade civil passa a ocupar uma posição de destaque, em que a cidadania emerge como protagonista do processo de construção e formulação das políticas públicas. Siedenberg (2012), indica mais que a eficiência, há necessidade de eficácia e efetividade nas políticas públicas, que cada vez mais devem contar com a participação da sociedade na sua definição, mas também no monitoramento da sua execução e permanente avaliação.

No Brasil o modelo gerencial de administração pública foi adotado em 1995, segundo Allebrandt (2012), que tinha como meta, o fortalecimento da democracia no país.

\subsection{Administração Pública Societal}

A vertente social deriva, no Brasil, dos movimentos sociais que mobilizaram o país durante o período ditatorial. Os movimentos contaram com apoio da Igreja Católica, através das Comunidades Eclesiásticas de Base - CEBs. Esse processo, associado aos movimentos sindicais, comunitários e de várias categorias profissionais, promoveram a criação de espaços, onde as pessoas eram estimuladas a debater as questões cotidianas, contribuindo para a formação de lideranças populares. Disso resultaram reivindicações populares junto ao poder público, sobre assuntos relacionados à qualidade de vida individual e coletiva.

Portanto, a origem do modelo social deve-se, ao anseio da sociedade em participar mais ativamente do governo. Para Klering, Porsse e Guadaginin (2010), a vertente societal é baseada em uma nova relação Estado-Sociedade, com maior envolvimento da população na definição da agenda política e consequentemente maior controle social sobre as ações estatais de forma a legitimar a participação popular no processo de formulação e implementação de políticas públicas.

\section{POLÍTICAS PÚBLICAS}

Inicialmente é importante compreender que as políticas públicas vêm se consolidando no campo de estudo das ciências sociais. Apesar de grandes transformações sociais, políticas e econômicas no cenário mundial e nacional, as políticas públicas se destacam como uma área do conhecimento.

Os estudos sobre políticas públicas são muito recentes, especialmente no Brasil, segundo Secchi (2010) apud Lima (2012), qualquer definição de política pública é desafiadora, não há consenso. Para Saravia e Ferrarezi (2006), trata-se de um fluxo de decisões públicas orientadas a manter o equilíbrio social.

No entender de Gelinski e Seibel (2008) as políticas públicas são ações governamentais que buscam solucionar determinadas necessidades públicas. Para Rua (2009) são processos de formulação, implementação, acompanhamento e avaliação.

Ainda para Gonçalves e Capella (2016), as políticas públicas são respostas para problemas percebidos pelo governo, o que não exclui a possiblidade das organizações não governamentais influenciarem, direcionar, controlar ou até mesmo contribuir na formulação de políticas públicas. 
Para Secchi (2010) apud Lima (2012) assim como Gonçalves e Capella (2016), definem que a essência conceitual de políticas públicas é o "problema público" onde a mesma tem a intenção de responder a um problema público. Souza (2006), afirma que não existe uma única, nem uma melhor definição, sobre o que sejam políticas públicas.

Portanto Mousquer, (2016) entende que as políticas públicas serão quase sempre, um desafio para o poder público, por serem voltadas para uma sociedade volúvel.

\subsection{Processo de Políticas Públicas}

No campo dos estudos das políticas públicas, corroboram Gonçalves e Capella (2016), ao indicarem que um dos primeiros recursos teórico-metodológicos, para entender as políticas públicas, resume-se na simplificação do processo, ao contemplar a fragmentação de seu conteúdo em modelos, etapas passíveis de análise.

A ideia das etapas ou fases, remete ao entendimento de que todas as políticas passariam pelos mesmos estágios, tal ideia permitiu não apenas simplificar o complexo processo de produção de políticas, destacando seus aspectos centrais (agenda, formulação, tomada de decisão, implementação, avaliação, entre outros) mas também impulsionou o desenvolvimento do próprio campo do conhecimento da área (GONÇALVES e CAPELLA, 2016).

Quanto aos principais modelos de políticas públicas segundo Souza (2006) e Gelinski e Seibel (2008), foram desenvolvidos alguns modelos para tentar compreender melhor como e por que o governo faz ou deixa de fazer alguma ação que venha a repercutir na vida dos cidadãos. Portanto, muitos foram os modelos desenvolvidos destacando-se o Incrementalismo, ciclo da política pública (Policy Cycle), modelo "garbage can" ou "lata de Lixo", Coalizão de defesa (Advocacy Coalition), Arenas sociais (Policy Networks), equilíbrio interrompido, novo gerencialismo público entre outros.

Assim, segundo Saravia e Ferrarezi (2006), cada política pública passa por diversos estágios, sendo necessário distinguir elaboração de formulação, pois a elaboração é a preparação da decisão política, a formulação, é a decisão política ou a decisão tomada por um ator político. Portanto, é possível verificar várias etapas ou fases num processo de política pública, são elas: identificação do problema, formação da agenda, formulação e alternativas, tomada de decisão, implementação, avaliação e extinção segundo Secchi (2010).

\subsection{O Ciclo da Política Pública}

O ciclo de política pública é o principal esquema heurístico utilizado para analisar políticas públicas. Este modelo é derivado da teoria geral dos sistemas e organiza a "vida" de uma política pública em fases sucessivas e interdependentes (SECCHI, 2012).

As políticas públicas se constituem de um conjunto articulado de etapas de caráter dinâmico e que podem sofrer modificações no processo de elaboração e implementação. Frey (2000, p.226) apud Gelinski; Seibel (2008), sugere a análise do clico político em cinco fases: (1) percepção e definição do problema, (2) 
montagem da agenda, (3) Formulação e tomada de decisão (4) Implementação e, finalmente (5) avaliação. Neste modelo, segundo Gelinski; Seibel (2008) prevalece à ideia de que uma política se inicia a partir da percepção de problemas e ainda em termos conceituais, em relação às classificações de três fases tradicionalmente propostas para o ciclo: formulação, implementação e controle.

Para Mattos; Baptista (2015), a ideia do modelo de fases da política talvez seja a perspectiva mais corrente e compartilhada nos estudos em política. Apesar das críticas ao modelo (caráter funcionalista, racional e que tenta manter o controle sobre o processo político), este persiste no debate acadêmico como referência.

O modelo de fases tem como principal contribuição a ideia de ciclo da política, ou seja, a possiblidade de percepção de que existem diferentes momentos no processo de construção de uma política, apontando para a necessidade se reconhecer as especificidades de cada um dos momentos e dessa forma possibilitar maior conhecimento e intervenção sobre o processo político. Quanto à desvantagem desse modelo, fica por conta da inevitável fragmentação que a ideia de fases provoca em qualquer análise a ser empreendida. Além disso, tem-se o perigo de se imaginar que nesse modelo a política se comporta de forma previsível (MATTOS; BAPTISTA, 2015).

\subsubsection{Percorrendo as Fases da Política Pública}

$\mathrm{Na}$ perspectiva do ciclo da Política Pública, de forma sucinta serão abordadas as cinco fases e sua importância no contexto do campo de estudo das políticas públicas.

A primeira fase compreende o primeiro passo, no desenvolvimento de uma política pública, o reconhecimento de um problema, que segundo Mattos e Baptista (2015), são os problemas que constituem o ponto de partida para a geração de uma política pública.

A segunda fase compreende a "montagem da agenda" que para Saravia e Ferrarezi (2006), é quando os problemas são organizados em uma lista de prioridades pelo poder público, ou seja, a dita "agenda", que pode ser classificada em sistêmica ou não governamental, e corresponde à lista de problemas que por algum motivo não despertam interesse do poder público. A agenda institucional ou governamental é aquela que inclui os problemas que são de interesse do governo, mas que ainda, não se apresentam na mesa de decisão, a agenda decisória ou política é aquela que corresponde à lista de problemas que estão sendo considerados no processo decisório para Mattos e Baptista (2015)

A terceira fase, compreende a formulação e tomada de decisão, na agenda governamental, ou seja, quando o governo entende a relevância do desafio, formula alternativas, possíveis soluções para o problema. Para Mattos e Baptista (2015), é a fase de tomada de decisão, em que são definidas as metas, os recursos a serem utilizados e o horizonte temporal da intervenção.

A implementação da política, corresponde a quarta fase do ciclo. É considerada a fase administrativa da política, ou seja, onde todo o controle está nas mãos dos 
"formuladores" e que de acordo com Saravia e Ferrarezi (2006), é constituída pelo planejamento e organização do aparelho administrativo e dos recursos humanos, financeiros, materiais e tecnológicos necessários para executar a política.

E por fim, a quinta fase, de avaliação da política, que segundo Ferreira (1999), significa determinar a valia de algo, atribuir um valor. Mas mesmo assim, ainda não existe um consenso quanto ao que seja avaliação de políticas públicas, uma vez que, o conceito admite múltiplas definições, algumas ainda que contraditórias. Ala-Harja e Helgason (2000) apud Trevisan e Bellen (2008), definem avaliação afirmando que é o resultado, de um programa em relação aos objetivos propostos. Para Barros Silva et al. (1999) apud Mattos; Baptista (2015), a avaliação é voltada também para avaliar o processo como um todo analisando suas etapas, mecanismos de operação e resultados esperados, onde se busca saber se os programas cumpriram seus objetivos, o quanto cumpriram e com que qualidade.

Assim, a avaliação passa ter a função de instrumento ao passo que, subsidia a tomada de decisão, nos mais variados momentos que ocorrem ao longo das diversas fases do ciclo. Faria (2005), indica o uso do instrumental, para tomada de decisão, que não depende apenas da qualidade da avaliação, mas também da adequada divulgação de seus resultados.

Em resumo, a avaliação consiste na mensuração e análise dos efeitos produzidos na sociedade, pelas políticas públicas.Portanto para Frey (2000, p.229) apud Trevisan e Bellen (2008), “a fase da avaliação é imprescindível para o desenvolvimento e a adaptação contínua das formas e instrumentos de ação pública". Ainda para os autores, os resultados das avaliações podem servir tanto como instrumento de tomada de decisão, como de divulgação, para o debate público em torno das alternativas de intervenção governamental, em uma dada realidade social, o que evidencia sua relevante importância no ciclo da política pública.

\section{PROGRAMA MELHOR INFÂNCIA UMA INOVAÇÃO EM POLÍTICA PÚBLICA}

\section{Programa Primeira Infância Melhor} (PIM), enfoca o desenvolvimento holístico da primeira infância em atividades que promovam o desenvolvimento cognitivo, psíquico e social da criança, fortalecendo os laços da família e da comunidade em que as crianças se inserem, bem como, a participação social (KAISER e FREITAS, 2010).

O PIM integra a política de governo do Estado do Rio Grande do Sul, tornou-se Lei Estadual no 12.544 em 03 de julho de 2006, para a promoção do desenvolvimento integral da primeira infância. Sob a coordenação da Secretaria Estadual da Saúde, com apoio das Secretarias da Educação, da Cultura, do Trabalho e do Desenvolvimento Social, da Justiça e dos Direitos Humanos e do Gabinete de Políticas Sociais, através de um comitê Gestor, que tem como objetivo a promoção de ações conjuntas, visando à implementação, o monitoramento e avaliação dos resultados do Programa segundo Bernardes (2010).

Desta forma, o PIM reflete na sua concepção, implantação e evolução o reconhecimento das singularidades e da importância do desenvolvimento nos primeiros 
anos de vida, constitui-se em um programa de ação socioeducativa com objetivo de orientar as famílias, através de sua cultura e experiências, para que promovam o desenvolvimento integral das crianças, da gestação até seis anos de idade. Portanto, significa o pleno desenvolvimento das capacidades físicas, intelectuais, sociais e emocionais do ser humano, tendo como eixos de sustentação a comunidade, a família e a intersetorialidade (RIO GRANDE DO SUL, 2016).

De acordo com Bernardes (2010) apud Ecker e Torres (2015), o PIM é uma política que surge para dar conta da falta de acesso da população mais pobre a educação infantil de qualidade, priorizando as áreas, cuja população se encontre em situação de vulnerabilidade e risco social e elevados índices de mortalidade infantil.

Schneider e Ramires (2007), afirmam que o PIM contribui para o rompimento do ciclo de pobreza nas famílias atendidas, através da potencialização de um cuidado especial, uma educação de qualidade. Desta forma, as ações do programa surgem como práticas inovadoras que possibilitam uma ação educativa, comprometida com os valores como: igualdade, responsabilidade e justiça em um processo de transformação, na busca da cidadania.

O PIM apresenta como referência teórico-metodológica o programa cubano "Educa a tu Hijo", que segundo Zorzan (2011), é o modelo de intervenção, na primeira infância, que poderá ser mais eficaz e próximo da realidade de organização da rede de serviços públicos no Rio Grande do Sul.
O Programa "Educa a tu Hijo", é coordenado pelo Centro de Referência Latinoamericano para La Educación Preescolar (CELEP), como uma metodologia de trabalho baseada em três eixos fundamentais de sustentação: a intersetoralidade, o caráter comunitário das ações e a abordagem focalizada na família (o protagonismo familiar).

Segundo Schneider e Ramires (2007) a política de intersetorialidade se faz importante, por se tratar das bases sólidas para todas as aprendizagens humanas e o programa "Educa a tu Hijo" serviu de modelo para o PIM, resguardadas as diferenças contextuais entre Cuba e Rio Grande do Sul. Desse modo, a proposta de criação de um programa envolve em suas equipes de execução, as Secretarias Estaduais e Municipais de Saúde, de Educação e de Assistência Social, devido a serem estas as áreas mais diretamente vinculadas ao referido público (ZORZAN, 2011; SCHNEIDER e RAMIRES, 2007).

Segundo Sanmartim e Bitencourt (2016), o PIM apresenta uma ótima aceitação pela sociedade, por que une iniciativas do estado, dos municípios e da sociedade civil, ao efetivar os direitos das crianças. Assim, essa política tem como premissa a valorização dos direitos da criança, e como desafio, a redução dos índices de desigualdade e exclusão social segundo Sanmartim e Bitencourt (2016).

Portanto, o Programa Primeira Infância poderá ser considerado uma inovação nas políticas públicas, que teve como base o programa cubano "Educa a tu Hijo" e adaptado ao contexto do estado do Rio Grande do Sul. 
O PIM vem acumulando excelentes resultados no processo avaliativo, com auxílio do SisPIM, outras pesquisas de órgãos oficiais como a Fundação Getúlio Vargas (FGV), Centro de Referência Latino-americano de Educacion Preescolar (CELEP) e Offord Centre for Child Development, da Universidade McMaster de Toronto/Canadá, avaliaram o PIM com resultados satisfatórios.

Significa que, o Programa poderá ser considerado uma inovação na organização dos serviços públicos, com melhorias e aprimoramentos das ferramentas e técnicas de monitoramento. Segundo Sanmartim e Bitencourt (2016), o suporte legal do PIM ainda não teve seu complemento em leis suficientemente abrangentes que possam responder com suficiência às exigências dos Tribunais de Contas.

\section{CONSIDERAÇÕES FINAIS}

O estudo permeia o panorama histórico e evolutivo da administração pública, contempla o surgimento da administração pública como disciplina. Trabalhou os modelos da administração pública: patrimonialista, burocrático e gerencial, as recentes tendências da administração pública com participação popular.

A pesquisa permite entender que as administrações públicas, cultivam traços e heranças das administrações patrimonialista, burocrática e gerencial, mesmo em um ambiente que apresenta rápidas mudanças, um acirramento da competição, tanto nacional como internacional, indica novos desafios para as configurações organizacionais, novas dinâmicas socioeconômicas no território, com potencial para conquista de novos modelos de gestão pública.

É bastante tentador afirmar, que as administrações se complementam, mas esta análise se tornaria extremamente desafiadora, ao olhar as diferenças entre as origens e os projetos políticos, na forma como estes conduzem a organização e a gestão. Além disso, é preciso reconhecer a natureza estrutural-funcionalista da abordagem gerencialista, claramente voltada para a estrutura e a eficiência da gestão em detrimento dos processos políticos.

$\mathrm{O}$ artigo, ao trabalhar a administração pública, apresenta uma lógica própria, requerendo o desenvolvimento de técnicas de gestão adequadas, além de uma formação específica para os gestores públicos. Isso desafia os governantes e pesquisadores a realizarem uma combinação entre a administração e a política, preservando o caráter crítico das ciências sociais. Dessa forma, ainda que o movimento gerencialista tenha tomado para si a intenção de fundar uma nova administração pública, esse é ainda um projeto em construção.

Merece uma atenção especial, o Programa Primeira Infância Melhor, como uma inovação em políticas públicas, por utilizar a intersetorialidade como eixo estruturante, ou seja, nessa perspectiva, as políticas públicas não devem ser entendidas como programas que se dividem por setores de acordo com as necessidades do Estado, ao contrário, elas devem estar interligadas de maneira contínua e serem compreendidas a partir da própria construção de instituição e processos políticos, que estão 
intimamente conectados com todas as questões que regem a sociedade.

Apesar dos desafios, o PIM serviu de referência para a criação, do recente aprovado, Marco Legal da Primeira Infância, que vem para fortalecer as ações voltadas ao infante de zero a seis anos de idade e gestantes, além de buscar fortalecer o vínculo e convivência familiar, através da criação de uma Política Nacional Integrada para a Primeira Infância, com abordagem e coordenação intersetorial principalmente entre educação, saúde, assistência social, através da corresponsabilidade da União, dos Estados e dos municípios, fortalecendo assim o desenvolvimento sadio de nossas crianças.

\section{REFERÊNCIAS}

ALLEBRANDT, Sérgio Luís. (2002): A Participação da Sociedade na Gestão Pública Local e na Produção das Políticas Públicas: a Atuação dos Conselhos Municipais de Ijuí - RS, de 1989 a 2000. Ijuí: Ed. Unijuí.

ALLEBRANDT, Sérgio Luís. (2012): Estado, Administração Pública e Gestão Social, In: SIEDENBERG, Dieter Rugard (Org.).

Desenvolvimento Sob Múltiplos Olhares. Ijuí: Unijuí.

AMATO, Pedro Muñoz. (1971): Introdução a Administração Pública. 2. ed. Rio de Janeiro: Fundação Getúlio Vargas.

BERNARDES, Karine Isis. (2010): Avaliação da Primeira Infância Melhor através de estudos de caso: $O$ encontro entre a educação forma e nãoformal. Dissertação de Mestrado em Educação, Programa de Pós-Graduação da Faculdade de Educação PUC-RS, Porto Alegre.

BIEGER, Thiago Beniz; THESING, Nelson José; MUELLER, Airton Adelar; HÖFLER, Cláudio Edilberto; FRITZEN, Adriano. (2017): Práticas de controle social como mecanismos de influência na tomada de decisões governamentais em Santa Rosa/RS. Revista Espacios, Caracas.

BRASIL. Congresso Nacional. (2018): Lei no 13.257, de 8 de março de 2016. Disponível em: <http://www.planalto.gov.br/ccivil_03/_ato20152018/2016/lei/L13257.htm>. Acesso em 29 de junho.
COSTIN, Cláudia. (2010): Administração Pública.

Rio de Janeiro: Elsevier.

DE PAULA. Ana Paula Paes. (2005b):

Administração Pública Brasileira entre o

Gerencialismo e a Gestão Social. RAE - Revista de Administração de Empresas, v. 45, n. 1, p.36-49, Rio de Janeiro, janeiro/março.

DE PAULA. Ana Paula Paes. (2005a): Por uma nova gestão pública: limites e potencialidades da experiência contemporânea. Rio de Janeiro: FGV.

ECKER, Daniel Dall'Igna; TORRES, Samantha. (2015): Relato de experiência no Programa PIM-

PIA: Políticas Públicas em Primeira Infância. Revista Percurso Acadêmico, Belo Horizonte, v.5, n.10, p.399-416, julho/dezembro.

FARAH, Marta Ferreira Santos. (2011): Administração Pública e Políticas Públicas. RAP Revista de Administração Pública, Rio de Janeiro, Maio/Junho.

FARIA, Carlos Aurélio Pimenta de. (2005): A Política da Avaliação de Políticas Públicas. RBCS Revista Brasileira de Ciências Sociais, v.20, n.59.

GELINSKI, Carmen Rosario Ortiz G; SEIBEL, Erni José. (2008): Formulação de Políticas Públicas: questões mesológicas relevantes.Revista de Ciências Humanas, Florianópolis, EDUFSC, v.42, n. 1e 2, p. 227-240, abril / outubro.

GOMES, Maria Lucineide Serpa; OLIVEIRA, Francisco Correia de. (2010): Modelos Organizacionais de Administração Pública: um estudo dos aspectos da realidade cearense na estrutura de referência das formas do Estado. Revista de Ciências da Administração, Vol. 12, n.28, p.105-126, setembro/dezembro.

GONÇALVES, Felipe Brasil; CAPELLA, Ana Cláudia Niedhardt. (2016): Os Estudos das Políticas Públicas no Brasil: passado, presente e caminhos futuros das pesquisas sobre análise de políticas. Revista Política hoje, v. 25, n. 1, p.71-90.

GRAU, Nuria Cunill. O duplo papel do público nãoestatal na reforma do Estado. In: NAKANO, Yoshiaki; REGO, José Marcio et. al. (orgs.). (2004): Em busca do novo: o Brasil e o desenvolvimento na obra de Bresser-Pereira. Rio de Janeiro: Editora FGV. KAISER, Dagmar Elaine; FREITAS, Talita Cristiane Sutter. (2010): Programa Primeira Infância Melhor: Percepção do visitador. Cienc Cuid Saude, jan./mar. p.81-90.

KLERING, Luís Roque; PORSSE, Melody de Campos Soares; GUADAGININ, Luís Alberto. (2010): Novos Caminhos da Administração Pública 
Brasileira. Análise, Porto Alegre, v.21, n.1, p.4-17, jan. /jun.

LIMA, Waner Gonçalves. (2012): Política Pública: discussão e conceitos. Revista Interface, Edição 5, Outubro.

MATTOS, Ruben Araujo; BAPTISTA, Tatiana Wargas de Faria. (2015): Caminhos para Análise das Políticas Públicas de Saúde. Ed.1, Porto Alegre: Rede UNIDA.

MOUSQUER, João Victor Magalhães. (2016): Estado e Gestão pública: O exercício da cidadania através de Políticas Públicas. Curitiba: Juruá.

RABELL, Leonardo Santana. (2000): Tendências curriculares em la enseñanza de la administracíon pública em los Estados Unidos. Reforma y Democracia, n.17.

RIO GRANDE DO SUL. (2018): PIM Programa Melhor Infância. <www.pim.saude.rs.gov.br> acesso em 26 junho.

RUA, Maria da Graça. (2009): Políticas Públicas. Florianópolis: Departamento de Ciências da Administração / UFSC.

SANMARTIM, Cleidiane; BITENCOURT, Caroline. (2016): O Marco Legal da Primeira Infância no Brasil e a Experiência Pioneira do Programa Primeira Infância Melhor (PIM) do Estado do Rio Grande do Sul. XII Seminário Nacional Demandas Sociais e Políticas na Sociedade Contemporânea, II Mostra Nacional de trabalhos Científicos, UNISC.

SARAVIA, Henrique; FERRAREZI, Elisabete. (2006): Políticas Públicas. Brasília: ENAP.

SCHNEIDER, Alessandra; RAMIRES, Vera R. (2007): Primeira Infância Melhor: Uma Inovação em Política Pública. Brasília: UNESCO, Secretaria Estadual do Rio Grande do Sul.

SECCHI, Leonardo. (2012): Formação da Agenda: Método de Policy Advocacy para Ensino de Políticas Públicas. APGS, Viçosa, v. 4, n. 1, pp. 32-47, jan. /mar.

SECCHI, Leonardo. (2009): Modelos organizacionais e reformas da Administração Pública. Revista de Administração Pública, v. 43, n. 2, p. 348-369, mar. /abr.

SECCHI, Leonardo. (2010): Políticas públicas: conceitos, esquemas de análise, casos práticos. São Paulo: Cengage Leaning.
SIEDENBERG, Dieter Rugard (Org.).(2012):

Desenvolvimento sob múltiplos olhares. Ijuí: Ed.

Unijuí, 400 p. - (Coleção Gestão e Desenvolvimento).

SILVA. Adival do Carmo. (2013): Evolução da Administração Pública no Brasil e tendências de novos modelos organizacionais. ICE - Instituto Cuiabano de Educação, Cuiabá. Disponível em <http://www.ice.edu.br/TNX/storage/webdisco/2013/1 2/13/outros/27b4d512efbac7d37520bc37aa78cac1.pdf $>$. Acesso em 22 junho.

SOUZA, Celina. (2006): Políticas Públicas: Uma revisão da literatura. Revista Sociologias, Porto Alegre, ano 8, n. 16, jul./dez, p.20-45.

TREVISAN, Andrei Pittol; BELLEN, Hans Michael Van. (2008): Avaliação de políticas públicas: uma revisão teórica de um campo em construção. RAP Revista de Administração Pública, Rio de Janeiro, p. 529-550.

WEBER, Max. (2009): Economia e Sociedade: Fundamentos da sociologia compreensiva. Editora UNB, v.4, Brasília.

ZORZAN, Scheila Paula. (2011): Gestão de Qualidade em Educação: A Experiência do Programa Primeira Infância Melhor. Dissertação de Mestrado em Educação, Programa de Pós-Graduação da Faculdade de Educação PUC-RS, Porto Alegre.

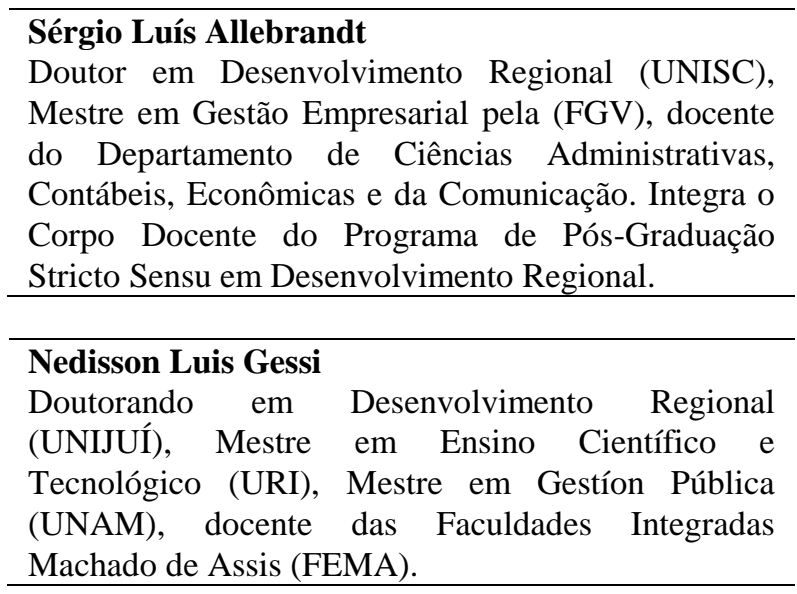

Nelson José Thesing

Doutor em Integração Regional. Professor do Departamento de Ciências Administrativas, Contábeis, Econômicas e da Comunicação. Integra o Corpo Docente do Programa de Pós-Graduação Stricto Sensu em Desenvolvimento Regional.

\section{Mauro Alberto Nuske}

Doutorando em Desenvolvimento Regional (UNIJUÍ), docente na Faculdade Três de Maio (SETREM). 


\section{Airton Adelar Mueller}

Pós-Doutorado (UNIJUI), Doutor em Sociologia pela

Freie Universität Berlin, Alemanha, Mestre em

Desenvolvimento Regional (UNISC). Integra o

Corpo Docente do Programa de Pós-Graduação Stricto Sensu em Desenvolvimento Regional.

Patrícia Rodrigues da Silva

Bacharel em Administração e Licenciada Plena em Pedagogia (SETREM), Aluna Especial do Mestrado em Desenvolvimento Regional (UNIJUÍ). 